\title{
Whole-Scalp Cobblestone Plica Neuropathica with Alopecia
}

\author{
Ana Filipe Monteiro ${ }^{a}$ André Lencastre ${ }^{b}$ \\ a Dermatovenereology Department, Hospital de Santarém EPE, Santarém, Portugal; ' ${ }^{b}$ Dermatovenereology \\ Department, Hospital de Santo António dos Capuchos, Centro Hospitalar de Lisboa Central, Lisbon, Portugal
}

\section{Established Facts}

- Plica neuropathica is a rarely reported acquired scalp condition.

- It may be associated with psychiatric disorders and neglect of scalp hygiene.

\section{Novel Insights}

- We report a case of plica "polonica” associated with severe alopecia.

- Plica "polonica" may show epidermal nevus-like histological features.

\section{Keywords}

Scalp disease $\cdot$ Neurodermatology $\cdot$ Alopecia $\cdot$ Epidermal nevus

\section{Abstract \\ Plica neuropathica (PN) is an uncommon scalp condition that usually presents as a compact mass of scalp hair. We re- port a case of a 55-year-old woman presenting with PN. She presented with a 40-year history of thick plaques of yellow scale afflicting the entire scalp, progressive alopecia, and seeming lack of care of her own condition. Histology showed epidermal nevus-like features and severe miniaturization.}

(c) 2019 S. Karger AG, Basel

\section{KARGER}

(c) 2019 S. Karger AG, Basel

E-Mail karger@karger.com

www.karger.com/sad

\section{Introduction}

Plica neuropathica $(\mathrm{PN})$ is a rare acquired disorder of the scalp characterized by irreversible entanglement of the hair resulting from gross neglect [1]. Other terms for this disorder include felting, bird's-nest hair, and plica "polonica" $[1,2]$. Although rarely described, the condition has been reported in association with psychiatric disorders, parasitic infestations, vesicobullous disorders, neglect of the scalp hair, and the use of shampoos with cationic surfactants [3]. Herein, we report a case of an exuberant cobblestone-like PN. 

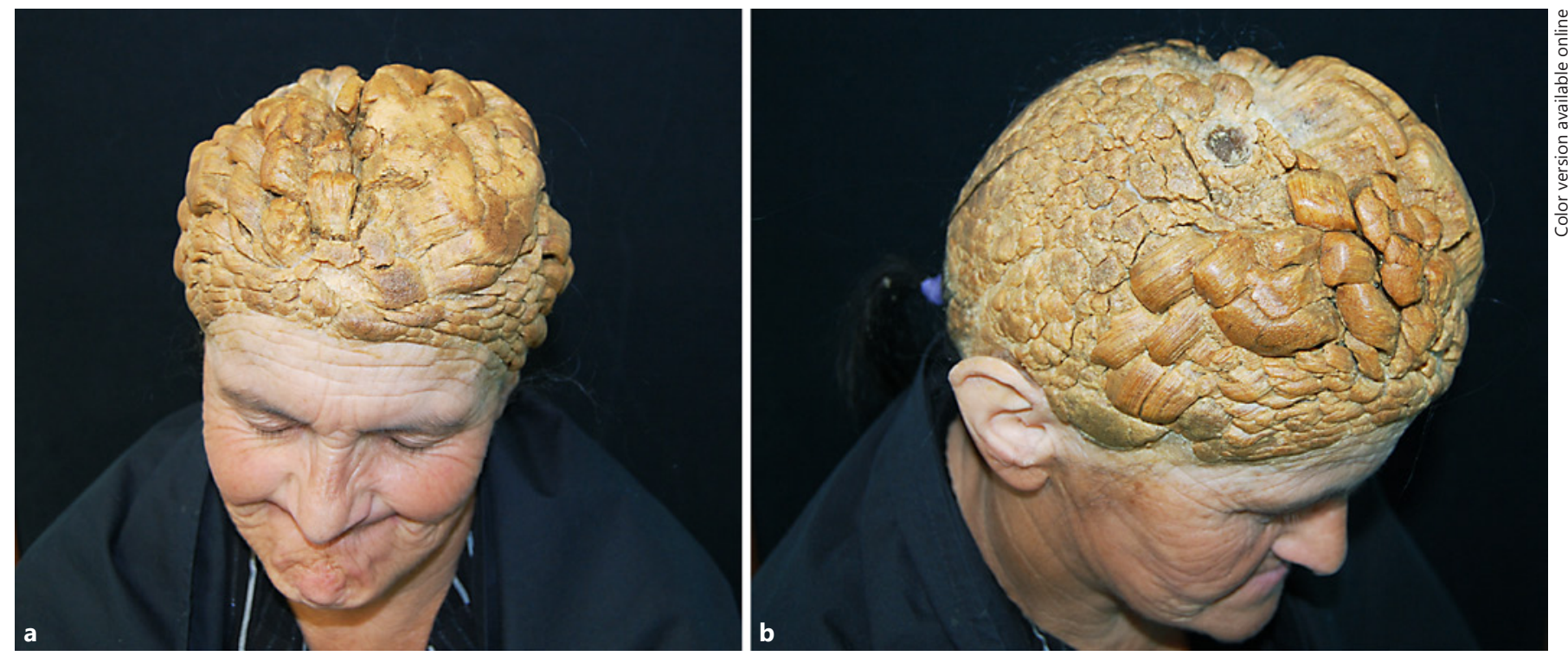

Fig. 1. Clinical examination. Front (a) and lateral right (b) view. Multiple, well-delimitated, verrucous plaques in a coalescent cobblestone pattern involving the entire scalp are shown.

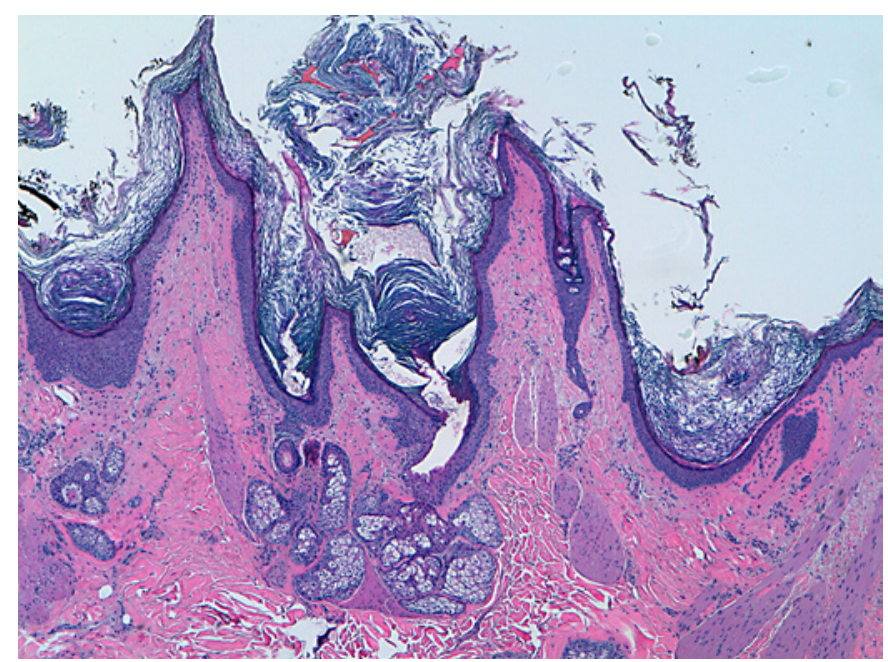

Fig. 2. Histology of the incisional biopsy. Hyperkeratosis with focal parakeratosis, epidermal hyperplasia with papillomatosis, and discrete acanthosis can be observed. Hematoxylin and eosin stain. Original magnification, $\times 40$.

\section{Case Report}

A 55-year-old Caucasian woman from a low socioeconomic reclusive rural background presented with a 40 -year history of a diffuse scalp dermatosis. Since childhood she had restrained herself from caring for her increasingly matted hair, cutting her hair, or properly addressing her scalp condition. She refrained from washing her hair and covered it with a scarf, daily. There was no relevant personal or familial history. She was otherwise healthy and a history of psychiatric illness was not disclosed. She displayed an evasive and distant demeanor and repeatedly contended that any care of her scalp would result in pain, scalp bleeding, or worsening.

The clinical examination revealed multiple, well-delimitated, verrucous plaques of thick, yellow-brown, and greasy scale distributed in a coalescent cobblestone pattern over the entire scalp (Fig. 1). It was possible to observe only scarce hair units in the occipital region. There was no associated itching or pain. The remaining cutaneous examination showed mere xerosis.

Three biopsy specimens at different sites on the scalp, revealed hyperkeratosis with focal parakeratosis, epidermal hyperplasia with papillomatosis, and discrete acanthosis (Fig. 2). Several fragments of horny scale were made of orthokeratotic corneocytes only and were devoid of any exogenous material. These findings excluded other inflammatory dermatoses, the distinct appearance of dirt or debris, and were reminiscent of epidermal nevi. Advanced miniaturization of hair was also found.

A diagnosis of PN with alopecia was subsequently made. The patient consistently refused our efforts to provide treatment, she remains negligent of her own condition, and referral to psychiatric evaluation has proven impossible.

\section{Discussion/Conclusion}

$\mathrm{PN}$ is a rarely reported acquired scalp condition characterized by irreversible entanglement of hair resulting from gross neglect $[1,2]$. Since the first description of PN by Le Page in 1884, there have only been a handful of cases describing this rare phenomenon [4]. The term "plica polonica" was very prevalent in Poland in the 19th cen- 
tury, when the Polish custom of wearing tight fur caps and not washing the hair contributed to a filthy and malodorous compact mass, usually associated with lice infection and inflammation of the scalp [5]. The pathogenesis of $\mathrm{PN}$ is unknown and poorly understood, and multifactorial causes have been accepted [5]. It has been associated with psychiatric disorders, ectoparasitoses, infections, psoriasis, seborrheic dermatitis, use of shampoos with cationic surfactants, drugs, and often with chronic neglect of scalp hair care [3, 6-8].

Our patient presented with a long-standing scalp dermatosis, lasting for decades according to the patient. The clinical presentation is exuberant and peculiarly combining thick greasy scale, areas of cutaneous horn appearance, and alopecia with miniaturization. These findings may be related to a long period of hair hygiene neglect that lead to PN. We cannot be sure if this condition may have contributed to hair miniaturization, or if the patient had concomitant female pattern alopecia.

All biopsy specimens closely resembled an epidermal nevus, which has been infrequently described in cases of plica polonica $[1,3,6,8]$. The biopsies also showed very thick orthokeratotic scale buildup only. The uniform cob- blestone clinical appearance with longstanding duration suggested an orderly epidermal proliferation involving the entire scalp, which we cannot exclude. We nevertheless favor the diagnosis of PN with alopecia.

To the best of our knowledge, this is the first case of $\mathrm{PN}$ associated with alopecia of the whole scalp and with epidermal nevus-like features.

\section{Statement of Ethics}

The patient has given consent to publish details and photos of the case.

\section{Disclosure Statement}

The authors have no conflicts of interest to declare.

\section{Funding Sources}

The authors have no funding sources to declare.

\section{References}

1 Marshall J, Parker C. Felted hair untangled. J Am Acad Dermatol. 1989 Apr;20(4):688-90.

2 Kwinter J, Weinstein M. Plica neuropathica: novel presentation of a rare disease. Clin Exp Dermatol. 2006 Nov;31(6):790-2.

3 Brar BK, Mahajan B, Kamra N. Felted hair in rupoid psoriasis: a rare association. Int $\mathrm{J}$ Trichology. 2014 Apr;6(2):69-70.

4 Le Plage JF. On neuropathica plica. Br Med J. 1884 Jan;1(1204):160.
5 Martins SS, Abraham LS, Doche I, Piraccini $\mathrm{BM}$, Vincenzi C, Tosti A. Acute hair matting: case report and trichoscopy findings. J Eur Acad Dermatol Venereol. 2017 Mar; 31(3):e163-4.

6 Osorio C, Fernandes K, Guedes J, Aguiar F, Silva Filho N, Lima RB, et al. Plica polonica secondary to seborrheic dermatitis. J Eur Acad Dermatol Venereol. 2016 Nov: 30(11):e134-5.
7 Gnanaraj P, Venugopal V, Pandurangan CN Plica polonica in association with pediculosis capitis and scabies - a case report. Int J Dermatol. 2007 Feb;46(2):151-2.

8 Ghodake NB, Singh N, Thappa DM. Plica neuropathica (polonica): clinical and dermoscopic features. Indian J Dermatol Venereol Leprol. 2013 Mar-Apr;79(2):269. 